\section{Studies on Water Transport Through the Sweet Cherry Fruit Surface: IV. Regions of Preferential Uptake}

\author{
Marco Beyer, Stefanie Peschel, and Moritz Knoche \\ Institute for Agronomy and Crop Science, Department of Horticulture, Martin- \\ Luther-University of Halle-Wittenberg, 06099 Halle (Saale), Germany
}

\author{
Manfred Knörgen \\ Department of Physics, Martin-Luther-University of Halle-Wittenberg, 06099 \\ Halle (Saale), Germany
}

Additional index words. water uptake, sweet cherry, Prunus avium, fruit, cracking, NMR

\begin{abstract}
Water uptake in different regions of the sweet cherry fruit (Prunus avium $\mathrm{L} . \mathrm{cv}$. Sam) was investigated following selective application of silicone sealant to the pedicel end, pedicel cavity, pedicel/fruit juncture, or stylar scar of detached fruit. The time course of water uptake was monitored gravimetrically during a 3-hour incubation period in deionized water $\left(20^{\circ} \mathrm{C}\right)$. Sealing the pedicel end and/or pedicel/fruit juncture significantly reduced rates and total amount ( 3 hours) of water uptake, but sealing the stylar scar had no effect. The amount of water penetrating via the pedicel/fruit juncture increased between 50 and 85 days after full bloom. During the same period the maximum force required to detach pedicels from fruit (fruit removal force) fell from $5.2 \pm 0.5$ to $2.1 \pm 0.2 \mathrm{~N}$. The amount of water penetrating via the pedicel/fruit juncture and the fruit removal force were negatively related. Nuclear magnetic resonance (NMR) imaging of mature fruit incubated in $\mathrm{D}_{2} \mathrm{O}$ indicated that $\mathrm{D}_{2} \mathrm{O}$ accumulated in the pedicel cavity region and the pedicel. Our data suggest that the pedicel end and pedicel/fruit juncture, but not the stylar scar, are regions of preferential water uptake in detached fruit. Chemical name used: deuterium oxide $\left(\mathrm{D}_{2} \mathrm{O}\right)$.
\end{abstract}

Rain-cracking of sweet cherry fruit causes severe losses in crop production (Cline et al., 1995; Sekse, 1995a), and cracking has been related to increased turgor resulting from penetration of water into the fruit (Christensen, 1996).

Studies on the distribution of cracks indicated that the pedicel cavity and stylar end regions are particularly prone to cracking (Sawada, 1934; Sekse, 1995b; Yamamoto et al., 1991). Two factors may account for these observations. First, mechanical stress may concentrate in pedicel cavity and stylar end regions of the fruit. Second, the fruit surface in these regions may be more permeable to water, resulting in rapid localized water uptake and, hence, cracking. In addition, rain water collects in the pedicel cavity and as a pendant droplet in the stylar end region, and may result in prolonged periods of water uptake.

Evidence for mechanical stress concentrating at polar regions is available, based on experimental data and theoretical considerations of stress distribution as affected by fruit geometry (Considine and Brown, 1981; Yamamoto et al., 1990). However, little is

Received for publication 26 Apr. 2001. Accepted for publication 8 Oct. 2001. We thank W. Meier and E. Sonnenkalb, Aseleben, Germany, for providing fruit samples; H. Rennebaum, E. Grimm, and M. Hinz for technical support and useful discussion; and F.G. Dennis and P.D. Petracek for critical comments on an earlier version of this manuscript. The financial support by the Deutsche Forschungsgemeinschaft (grant $\mathrm{KN} 402 / 4$ ) is appreciated. known about water absorption in different regions of the sweet cherry fruit surface. Davenport et al. (1972) investigated water uptake by sweet cherry fruit following selective application of an antitranspirant film but detected no regions of preferential water uptake. Unfortunately, the antitranspirant film employed lowered water uptake by only $50 \%$ when applied to the entire fruit surface, indicating that the barrier properties of the film were limited. Glenn and Poovaiah (1989) reported increased penetration of ${ }^{45} \mathrm{Ca}$ in the stylar scar area compared to the adjacent surface. Similarly, water conductance determined in a transpiration test using exocarp segments was higher when excised from the stylar end than from cheek or ventral suture regions (Knoche et al., 2000, 2002). To our knowledge, no direct data on water uptake through the fruit surface in the pedicel cavity region have been published. However, sealing the pedicel cavity with petroleum jelly before incubating fruit in water had no effect on cracking (Lane et al., 2000).

The objectives of our study were to establish whether regions of preferential water absorption are present on the surface of sweet cherry fruit. We focused on pedicel cavity and stylar end, since these regions are prone to extended periods of surface wetness.

\section{Materials and Methods}

Plantmaterial. Sweet cherry fruit (cv. Sam) were sampled from trees grafted on cv. Alkavo rootstocks in a commercial orchard (planting year 1989) located near Eisleben, Germany $\left(51^{\circ} 31^{\prime} \mathrm{N}, 11^{\circ} 44^{\prime} \mathrm{E}\right)$, in 1999 and 2000. Trees were cultivated according to current recommendations for integrated fruit production. Fruit selected for uniformity of development and freedom from defects after careful visual inspection were transferred to the laboratory within $1 \mathrm{~h}$ and held at $1{ }^{\circ} \mathrm{C}$ and $90 \%$ relative humidity for no longer than $48 \mathrm{~h}$.

\section{Experiments}

Water uptake per region. Water uptake through various regions of the fruit surface was determined using mature fruit [67 to $77 \mathrm{~d}$ after full bloom (DAFB)]. Unless otherwise specified, fruit pedicels were reduced to $2 \mathrm{~cm}$ in length at the atmosphere with a razor blade prior to initiation of the experiments. Subsequently, selected regions of the surface were coated with silicone sealant (Dow Corning 3140 RTV Coating; Dow Corning Corp., Midland, Mich.). The amount of silicone that was applied when sealing entire fruit averaged $\approx 2.8 \% \pm 0.1 \%$ of the fruit fresh mass. Following curing $(3 \mathrm{~h})$, fruit were immersed in deionized water $\left(20 \pm 1{ }^{\circ} \mathrm{C}\right)$. Water uptake was monitored gravimetrically after $0,0.16,0.3$, $0.5,1,2$, and 3 h using a microbalance (BP 211 D; Sartorius AG, 30707 Göttingen, Germany). Prior to weighing, water adhering to the fruit surface was removed by carefully blotting fruit with soft tissue paper. Preliminary experiments established that: 1) there was no detectable water absorption by silicone only when incubated in deionized water for up to $3 \mathrm{~h}$ (M. Beyer and M. Hinz, unpublished data); and 2) water penetration into fruit having the entire surface sealed with silicone was not significantly different from zero during a 3-h time interval (e.g., Fig. 2C), indicating that the silicone coating provided a highly effective barrier to water transport into the fruit.

The following experiments were performed:

Expt. 1. The pedicel end was sealed by dipping into silicone. For the treatment 'pedicel removed, hole sealed' the pedicel was gently removed by pulling, taking care that the cuticle around the pedicel/fruit juncture remained intact (Fig. $1 \mathrm{~A}$ and B). The resulting cavity above the stony pericarp was sealed with silicone such that the area covered by silicone corresponded with the area covered by the distal portion of the pedicel. Non-treated fruit served as a control in this and all subsequent experiments.

Expt. 2. Water uptake by excised pedicels (2-cm length) was studied by immersing pedicels in deionized water. Mesocarp tissue adhering to pedicels was removed with a razor blade before incubation.

Expt. 3. The effect of pedicel length on water uptake was studied by incubating fruit with pedicels reduced to 3.5 - or 1-cm length. In this experiment, fruit having the entire surface sealed, except for pedicel ends, served as controls. In a further treatment the entire surface, including pedicel and pedicel end, was sealed. 


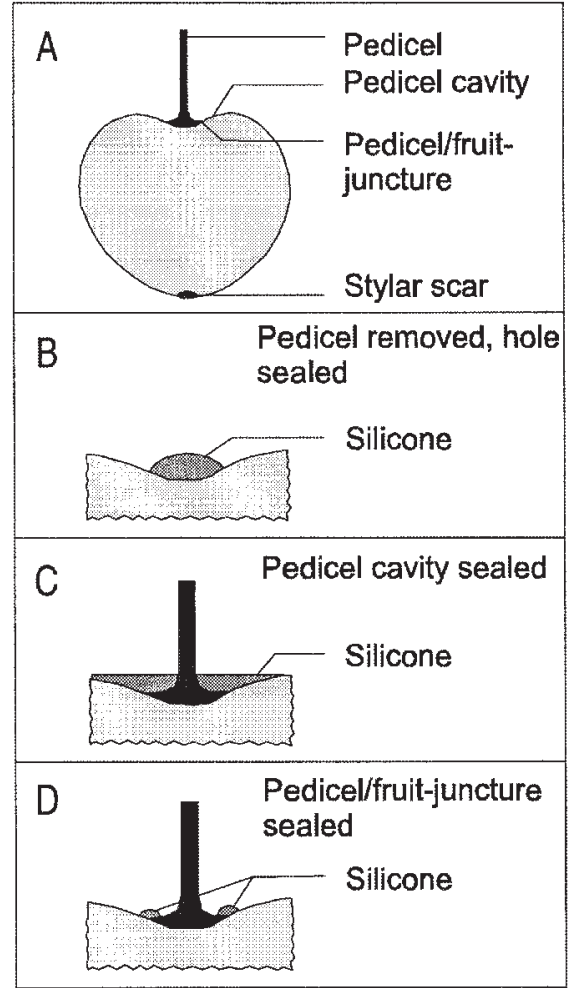

Fig. 1. (A) Schematic drawing of sweet cherry fruit. Detailed view of (B) pedicel cavity of fruit having the pedicel removed and the hole above the stony pericarp sealed, or $(\mathbf{C})$ the pedicel cavity sealed, or (D) the pedicel/fruit juncture sealed by silicone.

Expt. 4. To address water absorption in the pedicel cavity region, the pedicel cavity, including the pedicel/fruit juncture, was coated with silicone (Fig. 1C). A second treatment consisted of sealing the entire fruit surface, including pedicel and pedicel end, but not the pedicel cavity or pedicel/fruit juncture.

Expt. 5. Penetration through the pedicel/ fruit juncture was investigated by sealing the pedicel/fruit juncture with silicone or sealing the entire fruit, including pedicel and pedicel end except for the pedicel/fruit juncture (Fig. 1D).

Expt. 6. Penetration through the stylar scar was assessed by sealing the stylar scar only or sealing the entire fruit (including pedicel and pedicel end) except for the stylar scar.

Water uptake via the pedicel/fruit juncture in relation to fruit development. Fruit were harvested at weekly intervals between 50 and 85 DAFB covering early to late stage III of development. The commercial harvest period was from 67 to 77 DAFB. Water uptake of non-treated control fruit and fruit having the entire fruit surface sealed, including pedicel and pedicel end except for the pedicel/fruit juncture, was determined gravimetrically as described above following a 2-h incubation period. Subsequently, the maximum force $\left(\mathrm{F}_{\max }\right)$ required to detach pedicels from fruit was quantified using a universal materials testing machine (model Zwick 1446 and software package testXpert; Zwick $\mathrm{GmbH}$ and Co., Ulm, Germany). This force is referred to as the fruit removal force.
Nuclearmagnetic resonance (NMR) imaging. Mature fruit with or without pedicel ends sealed were incubated in deuterium oxide $\left(\mathrm{D}_{2} \mathrm{O}\right.$, 99.9\% pure; Cambridge Isotope Laboratories, Andover, Mass.) for $1 \mathrm{~h}$ at $20 \pm 1{ }^{\circ} \mathrm{C}$. Preliminary studies established that this time period was necessary to accumulate detectable amounts of $\mathrm{D}_{2} \mathrm{O}$ in the fruit. Following incubation, fruit were blotted, transferred to the NMR laboratory, and mounted in a custom-built sample holder. The holder was positioned in a Varian Unity $200 \mathrm{MHz}$ spectrometer (Varian NMR Systems, Palo Alto, Calif.) controlled by VNMR-software (Varian NMR Systems). There was no control of the microenvironment in the sample holder. Determinations were carried out at ambient temperature $\left(21 \pm 2{ }^{\circ} \mathrm{C}\right)$ and humidity. The deuterium NMR signal (30.7 MHz, Fourier-Imaging with 64 phase increments) was scanned for 1,2 , and $4.5 \mathrm{~h}$ using the following Hahn spin-echo pulse sequence: pulse $\left(0.8 \mathrm{~ms}, 90^{\circ}\right)$ - delay $(1.5 \mathrm{~ms})$ pulse $\left(440 \mu \mathrm{s}, 180^{\circ}\right)$ - echo (acquisition). Echo time was $3 \mathrm{~ms}$. Each pulse sequence was followed by a 2-s delay, which is 3.7 times as long as the relaxation time of $\mathrm{D}_{2} \mathrm{O}$ at $30{ }^{\circ} \mathrm{C}$ (Harries and Mann, 1978). Following the delay, the next pulse sequence was initiated. To achieve satisfactory signal : noise ratios, the $90^{\circ}$ pulse was performed at a gradient power of $0.2 \mathrm{~T} \cdot \mathrm{m}^{-1}$, resulting in an estimated thickness of the cross-section through the fruit of $\approx 2 \mathrm{~mm}$. The spectrometer was coupled to a microimaging system comprised of the following components: three PA10854 electronic amplifiers (Siems and Becker $\mathrm{GmbH}$, Bonn, Germany), a WSB-10 waveform synthesizer (Quatech, Akron, Ohio) and a custom-built gradient system for field gradients up to $1 \mathrm{~T} \cdot \mathrm{m}^{-1}$ (Heuert, 1998). The 64 phase increments obtained were subjected to a twodimensional Fourier-transformation that resulted in resolution of images of $512 \times 1024$ pixels. Comparable signal intensities were obtained by adjusting the vertical scale level of NMR-images. It should be pointed out that relative intensities of the $\mathrm{D}_{2} \mathrm{O}$ signal may be compared within a given image. Comparison between images, however, is limited, since there was no control of the microenvironment around the fruit during scanning and, hence, $\mathrm{D}_{2} \mathrm{O}$ losses due to transpiration were not standardized.

Following NMR experiments, selected regions of the fruit were examined for cracks by fluorescence microscopy at 100× (BX60 microscope; Olympus, Hamburg, Germany). Fruit were incubated for $2 \mathrm{~min}$ in a solution containing $0.1 \%$ (w/v) acridine orange (Merck Eurolab $\mathrm{GmbH}$, Darmstadt, Germany) and $0.1 \%(\mathrm{w} / \mathrm{v})$ of an organosilicone surfactant (Silwet ${ }^{\circledR}$ L-77; Witco, Düsseldorf, Germany) in $50 \mathrm{~mm}$ citrate buffer ( $\mathrm{pH}$ 6.5). Earlier studies established that this solution penetrated open stomata and cracks that extended through the fruit cuticle (S. Peschel and M. Knoche, unpublished data). Subsequently, fruit were removed from the dye solution and blotted. Exocarp segments were excised from the pedicel cavity and stylar end regions with a razor blade, transferred to the microscope stage, and investigated for cracks.

Statistical analysis. Experiments on water uptake were carried out with 10 single-fruit observations. Unless otherwise specified, data are presented as means \pm standard errors for fruit that remained without detectable cracks (by visual inspection) for the duration of the experiments ( $\geq 80 \%$ of the fruit). Where not shown, error bars were smaller than data symbols. Where appropriate, data were subjected to analysis of variance using general linear models (GLM) for repeated measurement designs (SAS program package version 6.12 ; SAS Institute Inc., Cary, N.C.). Regression analysis (procedures NLIN and REG for nonlinear and linear regression models, respectively; SAS Institute Inc.) was performed using individual observations.

\section{Results}

Water uptake per region. Water uptake increased with time (Fig. 2). Rates and total amount of water penetration differed among treatments. Rates of uptake of control fruit were higher initially $(0-1 \mathrm{~h})$, then approached an approximately constant rate of $12.2 \pm 2.2$ $\mathrm{mg} \cdot \mathrm{h}^{-1}$ between 1 and $3 \mathrm{~h}$ (Fig. 2A). In contrast, water uptake into fruit with pedicels removed or pedicel ends sealed proceeded at constant rates averaging $5.3 \pm 0.4$ and $10.4 \pm$ $0.5 \mathrm{mg} \cdot \mathrm{h}^{-1}$, respectively. Regression equations are as follows:

$$
\begin{aligned}
& \text { Pedicel removed: } \\
& \text { Uptake (mg per fruit) } \\
& \quad=-0.9( \pm 0.6)+5.3( \pm 0.4) \times \text { Time }(\mathrm{h}) \\
& \quad \mathrm{r}^{2}=0.70^{* * *} \\
& \text { Pedicel end sealed: } \\
& \text { Uptake (mg per fruit) } \\
& =-2.3( \pm 0.7)+10.4( \pm 0.5) \times \text { Time }(\mathrm{h}) \\
& \mathrm{r}^{2}=0.85^{* * *}(\text { Fig. } 2 \mathrm{~A})
\end{aligned}
$$

Total water uptake at $3 \mathrm{~h}$ was highest in control fruit $(44.1 \pm 4.5 \mathrm{mg})$, followed by fruit with pedicel ends sealed $(30.3 \pm 2.7 \mathrm{mg})$ and fruit with pedicels removed, hole sealed (15.8 $\pm 2.6 \mathrm{mg}$ ).

Excised pedicels absorbed water for $1 \mathrm{~h}$; thereafter, no further uptake occurred (Fig. 2B). Total pedicel uptake ( $3 \mathrm{~h}$ ) averaged 15.6 $\pm 0.9 \mathrm{mg}$ (equivalent to $33 \%$ by weight). Subtracting the average water uptake of excised pedicels at each time from that of control fruit yielded a constant uptake rate averaging $10.0 \pm 0.8 \mathrm{mg} \cdot \mathrm{h}^{-1}$. Regression equation is as follows:

$$
\begin{aligned}
\text { Uptake }(m g \text { per fruit }) \\
\\
=-3.0( \pm 1.2)+10.0( \pm 0.8) \times \text { Time }(\mathrm{h}) \\
\mathrm{r}^{2}=0.96^{* * *}(\text { Fig. } 2 \mathrm{~B})
\end{aligned}
$$

Pedicel length had no effect on water uptake, suggesting that water penetration through the pedicel surface was not a factor (Fig. 2C). In contrast, significant uptake occurred through the pedicel end of fruit in which the entire surface was sealed except for the pedicel end.

Data for water uptake in the pedicel cavity region were variable and somewhat inconsistent (Fig. 2 D and E). Uptake was unaffected by sealing the pedicel cavity, but readily occurred in fruit that was sealed except for the 


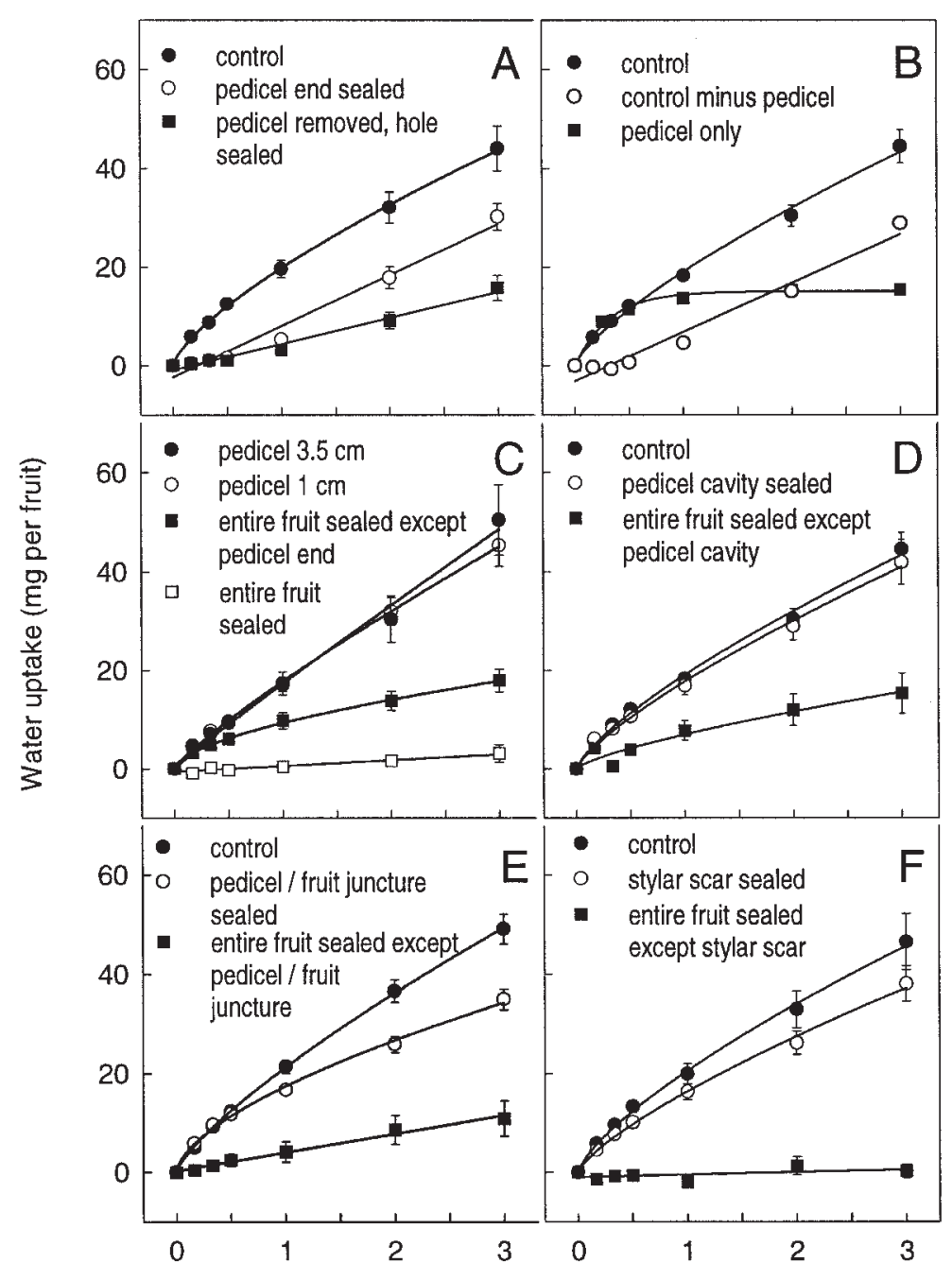

Time (h)

Fig. 2. Effects of sealing selected regions of the fruit surface of mature cv. Sam sweet cherry fruit on water uptake (Expts. 1-6). Treatments were: pedicel end sealed ("pedicel end sealed"); pedicel removed and hole above stony pericarp sealed ("pedicel removed, hole sealed"); excised pedicels ("pedicel only"); pedicel length reduced to 3.5 or $1 \mathrm{~cm}$ ("pedicel $3.5 \mathrm{~cm}$," "pedicel $1 \mathrm{~cm}$ "); entire fruit surface sealed, pedicel end open ("entire fruit sealed except pedicel end"); entire fruit surface and pedicel and pedicel end sealed ("entire fruit sealed"); pedicel cavity, including pedicel/fruit juncture, sealed ("pedicel cavity sealed"); entire fruit surface sealed except pedicel cavity and pedicel/fruit juncture ("entire fruit sealed except pedicel cavity"); pedicel/fruit juncture sealed ("pedicel/fruit juncture sealed"); entire fruit surface including pedicel and pedicel end sealed except for pedicel/fruit juncture ("entire fruit sealed except pedicel/fruit juncture"); stylar scar sealed ("stylar scar sealed"); entire fruit surface including pedicel and pedicel end sealed except for the stylar scar ("entire fruit sealed except stylar scar"). Non-treated fruit with pedicels and pedicel end open served as control ("control").

pedicel cavity (Fig. 2D). However, uptake was lowered in fruit having the pedicel/fruit juncture sealed and occurred in fruit that was sealed except for the pedicel/fruit juncture (Fig. 2E). Since sealing the pedicel cavity included sealing the pedicel/fruit juncture (Fig. $1 \mathrm{C}$ and D), we would have expected uptake also to decrease when the pedicel cavity was sealed (Fig. 2D).

Sealing the stylar scar had no significant effect on water uptake (Fig. 2F).

Water uptake via the pedicel/fruit juncture in relation to fruit development. There was no relationship between water uptake and fruit development for control fruit, but penetration through the pedicel/fruit juncture increased between 50 and 85 DAFB (Fig. 3A). In the same time interval, fruit removal force decreased linearly from $5.2 \pm 0.5$ to $2.1 \pm 0.2 \mathrm{~N}$, respectively (Fig. 3B). Plotting water uptake through the pedicel/fruit juncture vs. fruit removal force yielded a negative relationship (Fig. 4).

Nuclear magnetic resonance (NMR) imaging. Increasing the number of scans for the deuterium signal of a given fruit that was incubated in $\mathrm{D}_{2} \mathrm{O}$ markedly improved the signal : noise ratio (Fig. 5A-C). A 4.5-h accumulation time, equivalent to 176 scans, was selected for subsequent runs as a compromise between satisfactory resolution and loss of $\mathrm{D}_{2} \mathrm{O}$ due to transpiration and diffusion within the fruit. At 176 scans, $\mathrm{D}_{2} \mathrm{O}$ accumulation in pedicel and pedicel cavity region of control fruit was observed (Fig. 5D-F). When absorp-

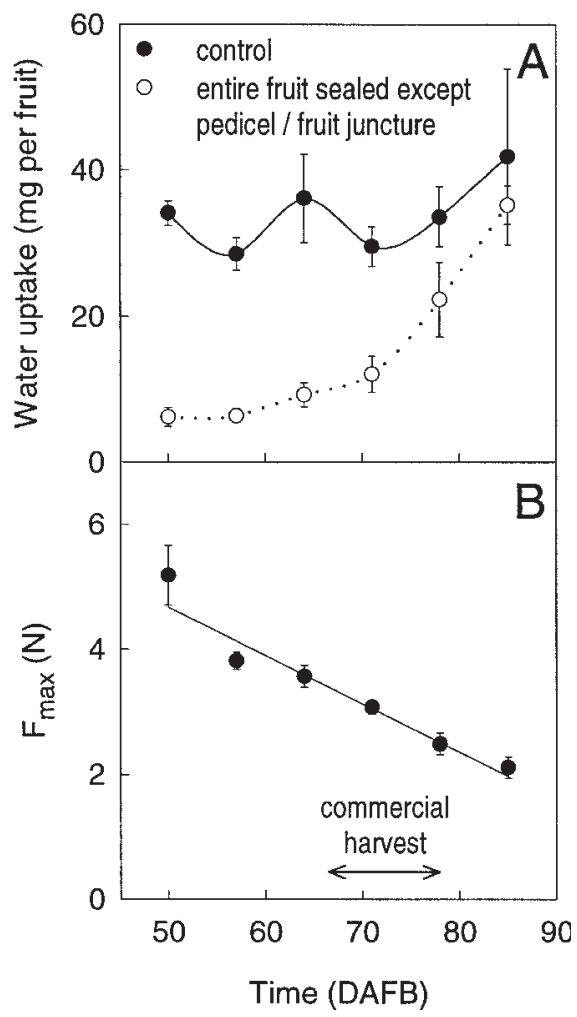

Fig. 3. (A) Water uptake of cv. Sam sweet cherry fruit in relation to fruit development. The entire fruit surface except for the pedicel/fruit juncture was sealed using silicone ("entire fruit sealed except pedicel/fruit juncture"). Nontreated fruit served as control. (B) Fruit removal force $\left(\mathrm{F}_{\max }\right)$ as related to fruit development. The regression equation for $\mathrm{F}_{\max } \mathrm{vs}$. time was:

$\mathrm{F}_{\max }(\mathrm{N})$

$=8.52( \pm 0.54)-0.08( \pm 0.01) \times$ Time $($ DAFB $)$

$\mathrm{r}^{2}=0.57^{* * *}$

Arrow denotes duration of commercial harvest.

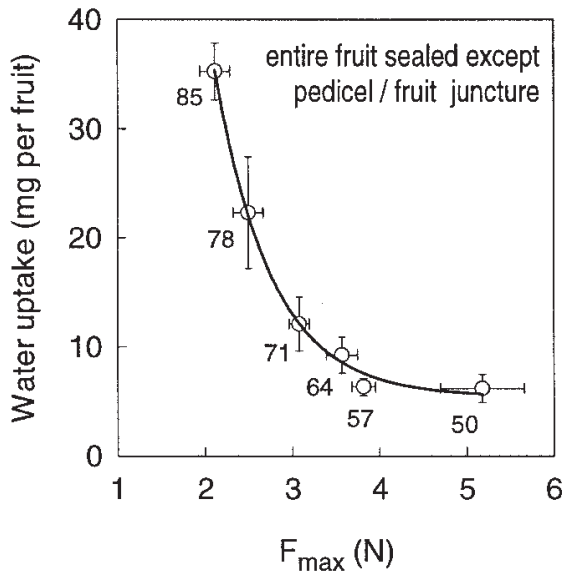

Fig. 4. Relationship between water uptake by fruit that was sealed except for the pedicel/fruit juncture and fruit removal force $\left(\mathrm{F}_{\max }\right)$. Numbers refer to time in days after full bloom. The regression equation was:

Uptake (mg per fruit)

$$
\begin{aligned}
& =5.4( \pm 0.8)+792.3( \pm 241.9) \exp [-1.5( \pm 0.1) \\
& \left.\times \mathrm{F}_{\max }(\mathrm{N})\right] \\
\mathrm{r}^{2} & =0.99^{* * * *} .
\end{aligned}
$$



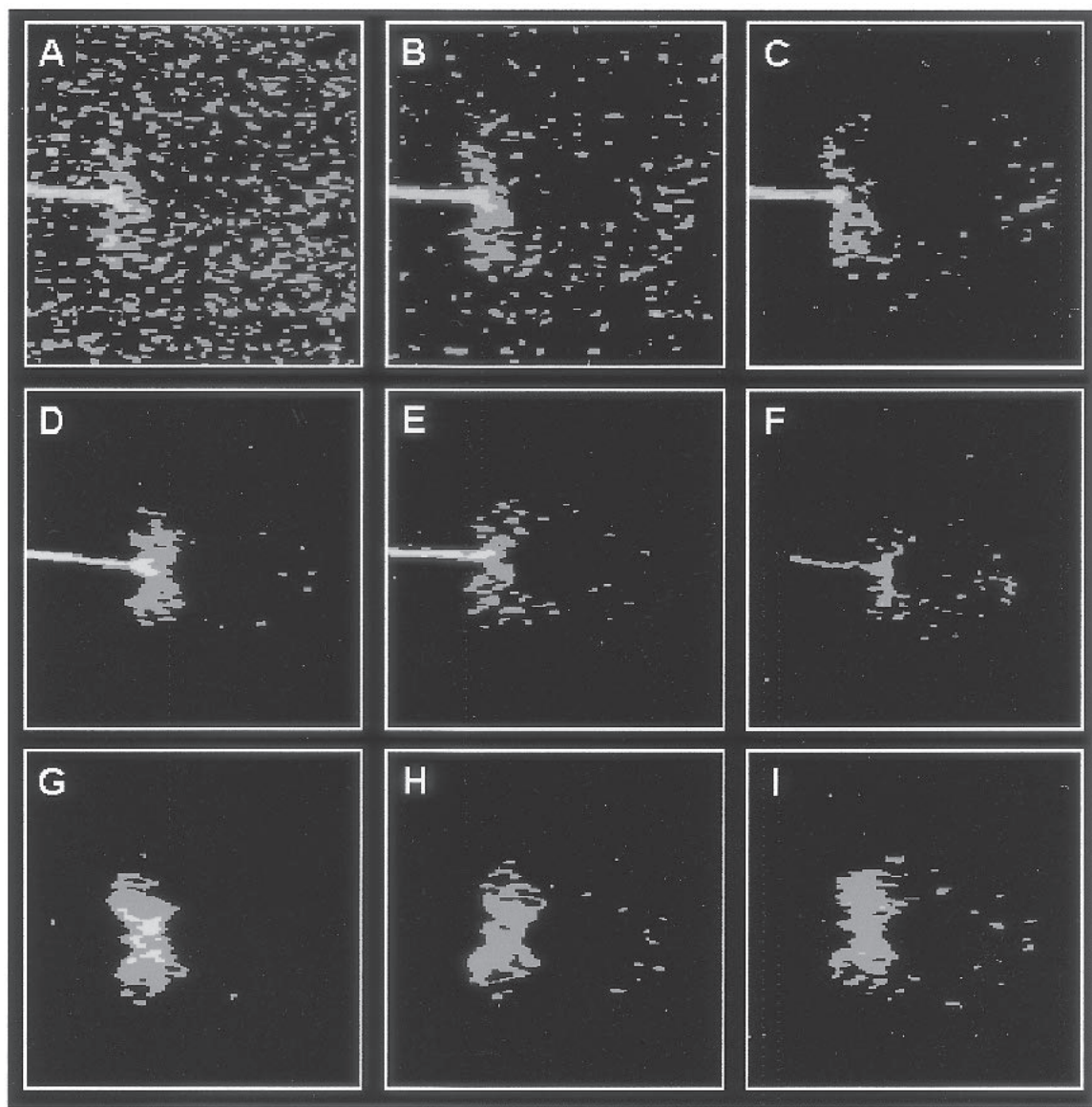

Fig. 5. $\mathrm{D}_{2} \mathrm{O}$-distribution in mature cv. Sam sweet cherry fruit after a 1-h incubation period in $\mathrm{D}_{2} \mathrm{O}$. The $\mathrm{D}_{2} \mathrm{O}$ signal of a given fruit accumulated for (A) 1 h, equiv. to 32 scans; (B) 2 h, equiv. to 64 scans, or (C) 4.5 h, equiv. to 176 scans. Representative images of $\mathrm{D}_{2} \mathrm{O}$ distribution (4.5-h accumulation period) in (DF) three control fruit with pedicel ends open and (G-I) three fruit with pedicel ends sealed with silicone. For details see materials and methods.

tion via pedicel ends was prevented by sealing them with silicone, no $\mathrm{D}_{2} \mathrm{O}$ accumulated in pedicels, and the NMR-signal from the pedicel cavity region remained relatively constant (Fig. 5G-I).

\section{Discussion}

The data presented in our study were obtained by monitoring water uptake in fruit having selected portions of the surface sealed by silicone. Silicone was a suitable sealant for this purpose, since there was essentially no detectable water uptake by sealed fruit. Also, with a single exception (Fig. 2D), the sum of uptake occurring in fruit having all but the region of interest sealed plus uptake by fruit having only the respective region of interest sealed was similar to uptake by control fruit. This observation indicated that the silicone coating did not limit the volume increase associated with water uptake by sweet cherry fruit. The data thus obtained demonstrate that the pedicel end and the pedicel/fruit juncture, but not the stylar scar, represent potential regions of preferential water uptake into detached sweet cherry fruit.

Penetration via the pedicel end. Allowing water uptake via the pedicel end consistently resulted in lower initial rates of uptake during the first $1 \mathrm{~h}$ of the experiment, while uptake thereafter occurred at a constant rate, as reported by Christensen (1972), Cline et al. (1995), and Wade (1988). The higher initial rate may be due to filling of a compartment that is associated with the pedicel. This interpretation is supported by the following observations: 1) incubating detached pedicels resulted in initially rapid uptake that approached an asymptote within $1 \mathrm{~h}$; 2) subtracting water uptake by excised pedicels from uptake into fruit with pedicel ends open resulted in a linear time course for penetration and the uptake rate thus obtained was not significantly different from the one determined experimentally using fruit with pedicel ends sealed $\left(10.0 \pm 0.8 \mathrm{mg} \cdot \mathrm{h}^{-1}\right.$ vs. $10.4 \pm 0.5 \mathrm{mg} \cdot \mathrm{h}^{-1}$, respectively); 3) fruit pedicels were labeled with $\mathrm{D}_{2} \mathrm{O}$ when penetration was allowed to occur through them, but not when they were sealed; and 4) cracking indices determined using the protocol by Christensen (1996) were similar for cv. Sam fruit with pedicel ends open in comparison with those with pedicel ends sealed (54.4 vs. 46.4, respectively; M. Beyer and M. Hinz, unpublished data). This evidence suggests that once the pedicel compartment was equilibrated with water, the pedicel did not contribute to water uptake in detached fruit. Clearly, the observation of up- take of free water through the pedicel end is relevant only to studies using detached fruit. In a whole-tree situation, the pedicel end would be linked to a non-interrupted water column in the xylem held under the trees water potential.

Penetration via the pedicel/fruit juncture. NMR and gravimetric monitoring of water uptake indicated that the pedicel/fruit juncture represented a region of preferential water uptake by mature and overmature fruit. Interestingly, fruit removal force decreases during maturation in sweet and sour cherry (Bukovac et al., 1969; Stösser et al., 1969); in sour cherry this decrease is associated with formation of an abscission zone at the pedicel/fruit juncture (Bukovac, 1971; Stösser et al., 1969). In contrast, there is no evidence for an abscission layer at the pedicel/fruit juncture in sweet cherry (Stösser et al., 1969). In our study we observed a comparable decrease in fruit removal force between 50 and 85 DAFB, indicating loosening of the pedicel/fruit juncture that may allow more water to enter the fruit. In addition, fluorescence microscopy of segments excised from the pedicel cavity region, including the immediate vicinity of the pedicel/fruit juncture, revealed microscopic cracks on all fruit that appeared sound on careful visual inspection (S. Peschel, unpublished data). These cracks, also observed in other studies (Glenn and Poovaiah, 1989; Knoche et al., 2000), may provide parallel pathways for water penetration into the fruit, although their contribution to total water uptake is unknown. At present we do not know whether microscopic cracks are a cause or a consequence of rapid water uptake in the region of the pedicel/ fruit juncture.

Preferential uptake in the region of the pedicel/fruit juncture may be of significant practical importance. First, following rain the pedicel cavity is characterized by extended periods of wetness, and this, together with preferential penetration along the pedicel/fruit juncture, may cause rapid water uptake and possible cracking. In fact, Christensen (1973) reported an increase in cracking of cv. Sam sweet cherry fruit from $\approx 25 \%$ to $100 \%$ between 70 and 80 DAFB, when fruit removal force in our study fell markedly (Fig. 3B) and water uptake along the pedicel/fruit juncture increased (Fig. 3A). Second, in many studies water uptake or fruit cracking has been highly variable (e.g., Christensen, 1973, 1996). Water uptake via the pedicel/fruit juncture is likely to contribute to this variability for several reasons. First, we observed a 2.9 -fold increase in water uptake via the pedicel/fruit juncture over a comparatively short time interval (71 to 85 DAFB). Second, the fruit removal force on a tree basis followed a normal distribution in sour cherry (Bukovac et al., 1969), and we expect a similar distribution for fruit removal force and, possibly, water uptake via the pedicel/fruit juncture in sweet cherry fruit. Third, mechanical stress resulting from wind or spray application with air blast sprayers may weaken the pedicel/fruit juncture, depending on pedicel length, fruit mass, and position of the fruit within the tree (Cooke, 1972), that may cause additional variability in 
water uptake and, hence, cracking. Fourth, provided that cracks contribute to water uptake, the amount of water penetrating through them should be highly variable.

In summary, our data revealed preferential water uptake through the pedicel/fruit juncture that may be related to a loosening of the juncture or possibly to microscopic cracks on the fruit surface in the immediate vicinity of the juncture. The relative contribution of this water uptake to total uptake increased as maturity proceeded. This observation emphasizes the need for a timely harvest of the sweet cherry crop. Further, sweet cherry varieties differ in volume of the pedicel cavity. Since the amount of water retained on the fruit is potentially available for uptake, the volume of the pedicel cavity may become a factor in water uptake and hence, cracking. The finding that uptake occurred also via the pedicel end has limited applications to attached fruit in an orchard situation, but may be relevant to laboratory studies where fruit is incubated with pedicel ends immersed in water as is often done when determining cracking indices. The data obtained with cv. Sam suggest that this uptake had no effect on the cracking index. However, this may not necessarily hold for other varieties.

\section{Literature Cited}

Bukovac, M.J. 1971. The nature and chemical promotion of abscission in maturing cherry fruit. HortScience 6:385-388.

Bukovac, M.J., F. Zucconi, R.P. Larsen, and C.D. Kesner. 1969. Chemical promotion of fruit ab- scission in cherries and plums with special reference to 2-chloroethylphosphonic acid. J. Amer. Soc. Hort. Sci. 94:226-230.

Christensen, J.V. 1972. Cracking in cherries. III. Physiological studies of the mechanisms of cracking. Acta Agr. Scand. 22:153-162.

Christensen, J.V. 1973. Cracking in cherries. VI. Cracking susceptibility in relation to the growth rhythm of the fruit. Acta Agr. Scand. 23:52-54.

Christensen, J.V. 1996. Rain-induced cracking of sweet cherries. Its causes and prevention, $\mathrm{p}$. 297-327. In: A.D. Webster and N.E. Looney (eds.). Cherries. CAB Intl., Oxon, U.K.

Cline, J.A., L. Sekse, M. Meland, and A.D. Webster. 1995. Rain-induced fruit cracking of sweet cherries. I. Influence of cultivar and rootstock on fruit water absorption, cracking and quality. Acta Agr. Scand. 45:213-223.

Considine, J. and K. Brown. 1981. Physical aspects of fruit growth. Plant Physiol. 68:371-376.

Cooke, J.R. and R.H. Rand. 1972. A mathematical interpretation of vibratory fruit harvesting. A tutorial paper, p. 1-17. Amer. Soc. Agr. Eng., St. Joseph, Mich., Paper No. 72-567.

Davenport, D.C., K. Uriu, and R.M. Hagan. 1972. Antitranspirant film: Curtailing intake of external water by cherry fruit to reduce cracking. HortScience 7:507-508.

Glenn, G.M. and B.W. Poovaiah. 1989. Cuticular properties and postharvest calcium applications influence cracking of sweet cherries. J. Amer. Soc. Hort. Sci. 114:781-788.

Harries, R.K. and B.E. Mann. 1978. NMR and the periodic table. Academic Press, London, U.K

Heuert, U. 1998. Konstruktion, Aufbau und Test eines NMR-Imaging-Zusatzes zur Untersuchung struktureller und dynamischer Inhomogenitäten in polymeren Materialien. PhD Diss., MartinLuther-University Halle-Wittenberg.

Knoche, M., S. Peschel, M. Hinz, and M.J. Bukovac.
2000. Studies on water transport through the sweet cherry fruit surface. Characterizing conductance of the cuticular membrane using pericarp segments. Planta 212:127-135.

Knoche, M., S. Peschel, and M. Hinz. 2002. Studies on water transport through the sweet cherry fruit surface: III. Conductance of the cuticle in relation to fruit size. Physiol. Plant. 114:414-421.

Lane, W.D., M. Meheriuk, and D.L. McKenzie. 2000. Fruit cracking of a susceptible, an intermediate, and a resistant sweet cherry cultivar. HortScience 35:239-242.

Sawada, E. 1934. A physical consideration of the mechanism of fruit cracking of sweet cherries. Trans. Sapporo Natl. Hist. Soc. 13:365-376.

Sekse, L. 1995a. Fruit cracking in sweet cherries Prunus avium L. Some physiological aspectsA mini review. Scientia Hort. 63:135-141.

Sekse, L. 1995b. Cuticular fracturing in fruits of sweet cherry Prunus avium L. resulting from changes in soil water contents. J. Hort. Sci. 70:631-635.

Stösser, R., H.P. Rasmussen, and M.J. Bukovac. 1969. A histological study of abscission layer formation in cherry fruits during maturation. $\mathrm{J}$. Amer. Soc. Hort. Sci. 94:239-243.

Wade, N.L. 1988. Effect of metabolic inhibitors on cracking of sweet cherry fruit. Scientia Hort. 34:239-248.

Yamamoto, T., K. Hosoi, and S. Watanabe. 1990. Relationship between the degree of fruit cracking and the distribution of surface stress of the fruit analysed by a newly developed system (in Japanese, with English abstract). J. Jpn. Soc. Hort. Sci. 59:509-517.

Yamamoto, T., H. Satoh, and S. Watanabe. 1991. Cracking index, fracture patterns and distribution on the fruit surface of several sweet cherry cultivars (in Japanese, with English abstract). J. Yamataga Agr. For. Soc. 48:75-78. 